\title{
A New Consumption-based Accounting model for Greenhouse Gases from 1948 to 2012
}

\author{
Zhiyong Yang ${ }^{1,5}$, Ting Wei ${ }^{2}$ J C Moore ${ }^{3,4}$, Jieming Chou ${ }^{1}$, Wenjie Dong ${ }^{1}$, \\ Rufeng Dai ${ }^{1}$, Shili Yang ${ }^{1}$, Jinghan Ban ${ }^{1}$ \\ ${ }^{1}$ The State Key Laboratory of Earth Surface Processes and Resource Ecology, \\ Beijing Normal University, Beijing 100875, China \\ ${ }^{2}$ Chinese Academy of Meteorological Sciences, Beijing 100081, China \\ ${ }^{3}$ College of Global Change and Earth System Science, Beijing Normal \\ University, Beijing 100875, China \\ ${ }^{4}$ Arctic Centre, University of Lapland, PL122, 96100 Rovaniemi, Finland \\ E-mail: corresponding author bnuyzy@gmail.com
}

\begin{abstract}
Greenhouse gas emissions embodied in international trade have grown rapidly as globalization has progressed and potentially threaten the efficacy of unilateral climate treaties such as the Kyoto Protocol. Consumption-based methods have been put forward as a way of overcoming this issue and help design future climate policies. We improve the Long-term Consumption-based Accounting (LCBA) model, with transfer carbon data from 1948 to 2012 by introducing country-specific import intensities and detailed bilateral trade data from UNCOMTRADE. Comparisons of our new "LCBA2" model with existing 4 studies show similar consumption based emission patterns both in trend and magnitude, and significant emission changes in many European countries. The results independently confirm previous findings on the efficacy of the Kyoto Protocol. The results indicate transferred emissions have contributed an historic $36 \mathrm{Gt} \mathrm{CO}_{2}$ of cumulative emissions, have grown rapidly during the past 30 years (up to $8 \%$ of total emissions) and are likely to become increasingly influential in the near future as the global economy recovers. We also use the improved model to study other gases $\left(\mathrm{CH}_{4}, \mathrm{~N}_{2} \mathrm{O}\right.$ and $\left.\mathrm{SO}_{2}\right)$ embodied in trade, and results indicate similar transfer patterns as $\mathrm{CO}_{2}$ with comparable or even moderately larger magnitudes. Across method differences between LCBA2 with EORA, GRAM and TSTRD are analyzed based on using common input datasets. Large emitters show moderate biases (within 10\%) and about $75 \%$ of countries have differences within $25 \%$, independent of input dataset. The LCBA2 model provides useful estimates of transferred emissions in both across-country and long-term historical contexts.
\end{abstract}

Keywords: greenhouse gases, emissions embodied in trade, carbon leakage, consumption-based emissions

5 to whom correspondence should be addressed 


\section{Introduction}

A growing number of countries have implemented policies to regulate carbon emissions within their borders. However, the true impacts of these policies have been questioned due to soaring trade interactions and emission transfers among countries (Peters and Hertwich 2008, Aichele and Felbermayr 2012, Andrew et al 2013, Kanemoto et al 2014). These phenomena are often called carbon leakage (Peters and Hertwich 2008, Davis and Caldeira 2010, Jacob et al 2014) and can be induced by both "policy" (strong carbon leakage) and "consumption" (weak carbon leakage). Although strong carbon leakage and the relevant "pollution haven hypothesis" are of serious concern, ex post econometric studies do not show statistically significant evidence of them (Branger and Quirion 2014). Weak carbon leakage, however, is broader in concept, unrelated to policies, and often triggered by comparative advantages, endowments and factor productivity in different countries (Weber and Peters, 2009, Peters et al 2009, Jakob and Marschinski 2013). In this study, we focus on weak carbon leakage and attempt to analyze the transferred emissions embodied in trade and their long-term patterns. These emissions are shown to be a significant factor in explaining emission changes in many countries (Nakano et al 2009, Davis and Caldeira 2010, Peters et al 2011b), especially for large emitters such as China (Weber et al 2008, Guan et al 2009, Minx et al 2011), the USA (Weber and Matthews 2007) and the UK (Baiocchi and Minx 2010, Wiedmann et al 2010, Barrett et al 2013). Recent studies also indicate that the Kyoto Protocol may be failing to fulfill its carbon-reduction purpose (Aichele and Felbermayr 2012, Peters et al 2011b, Kanemoto et al 2014) due to these ever growing emission transfers. Although there are doubts and critiques regarding the use of transferred and consumption-based emissions in future policy design, such as efficiency (Steckel et al 2010), insourcing nature (Liu 2015), justice and cost-effectiveness (Steininger et al 2014), responsibility attribution (Jakob and Marschinski 2013) and leakage settlement (Jacob et al 2013, 2014), the accounting method itself is a useful complement to the current production-based system and can provide a solid foundation upon which to settle these debates in the future.

Most empirical research on consumption-based emissions and emission transfers has been implemented using Multi-Regional Input-output (MRIO) models (Peters and Hertwich 2004, Lenzen et al 2004, Peters et al 2011a, Kanemoto et al 2014) and has focused on specific years (Peters and Hertwich 2008, Nakano et al 2009, Davis and Caldeira 2010, Davis et al 2011, Andrew et al 2013). The very large data requirements limit the ability of the input-output framework to track changes over time (Peters et al 2012a, 2011b, Caldeira and Davis 2011, Miller and Blair 2009). Due to recent advancements in constructing MRIO databases (Tukker and Dietzenbacher 2013, Dietzenbacher et al 2013, Andrew and Peters 2013, Meng et al 2013) and comparison work (Inomata and Owen 2014, Moran and Wood 2014, Owen et al 2014, Arto 
et al 2014, Geschke et al 2014), some studies have transcended this limitation and conducted time-series analyses at the global scale over the period from 1990-2010 (Peters et al 2011b, 2012b, Calderia and Davis 2011, Wiebe et al 2012, Lenzen et al 2012, 2013, Arto et al 2012). Peters et al (2011b) developed a time-series algorithm (TSTRD) to achieve long time series with trade data to estimate consumption-based emissions successfully. Wiebe et al (2012) set up the Global Resource Accounting Model (GRAM) using linear interpolation to fill in missing data in input-output and final demand tables. Lenzen et al $(2012,2013)$ developed a long term MRIO database (called EORA, which provides a completely harmonized and balanced world MRIO table) by specifying initial estimates and applying a quadratic programming approach to balance external constraint information such as merchandise trade, aggregate data and input-output tables. Kanemoto et al (2014) further extend the EORA database to backdate consumption-based emissions to 1970. Arto et al (2012) estimated the 1995-2008 resource use footprint of nations using the traditional MRIO method based on the World Input-Output Database (WIOD) project (Timmer 2012, Dietzenbacher et al 2013). All these studies help backdate historical data, facilitate the establishment of regular carbon footprint monitoring schemes and provide the foundation to complement the current production-based accounting system.

Previous research based on MRIO databases constructs carbon emission transfers beginning in 1990, limiting our understanding of the spatial and temporal patterns of transferred emissions. Therefore, long term (over 60 years) transferred emission data is needed. Not only because it can display long term patterns, but also because it can be used to set up new scenarios of consumption-based emissions in contrast to the territorial ones for different countries/groups. And these scenarios can be used as external forcing data and be put into climate models in order to research the climatic impact of transfer emissions (Wei et al 2012, 2016). To further backdate these data, Yang et al (2014) set up a new framework called LCBA (Long-term Consumption-based Accounting model) for estimating historical emission transfers since 1948. However, the LCBA model ignored regional disparities merely assuming global averages for "importation intensity", which affects the credibility of the results. We address this problem here by grouping countries using a hierarchical clustering method based on their emissions per GDP and dynamic time warping algorithm, and increased use of bilateral trade data from the UNcomtrade database (UN 2014). We show results for 164 countries over the period from 1948-2012 (Table S1-S2). Furthermore, we show that the improved LCBA model (hereinafter LCBA2) is effective in calculating transfers of non- $\mathrm{CO}_{2}$ greenhouse gases (e.g. $\mathrm{CH}_{4}$ and $\mathrm{N}_{2} \mathrm{O}$, 1970-2011, tables S3-S4) and air pollutants (e.g. SO 2 , 1948-2005, tables S5-S6). These new results from LCBA2 independently confirm previous findings on the efficacy of the Kyoto Protocol. Although our error analysis shows that results are greatly influenced by the 
calculation framework even after harmonization of territorial emissions, for large emitters, differences among datasets are always within $\pm 10 \%$.

\section{Materials and Methods}

\subsection{LCBA2 model}

This study improves the original LCBA model described in Yang et al (2014):

$$
\begin{gathered}
F_{C r}(r, i)=F_{P r}(r, i)+C O E F_{i m}(r, i) * \operatorname{Imports}(r, i)-\operatorname{COEF}(r, i) * \operatorname{Exports}(r, i) \\
\text { s.t. } \sum_{r}(\operatorname{COEF}(r, i) * \operatorname{Exports}(r, i))=\sum_{r}\left(\operatorname{COEF}_{i m}(r, i) * \operatorname{Imports}(r, i)\right) \\
\sum_{r} F_{P r}(r, i)=\sum_{r} F_{C r}(r, i)
\end{gathered}
$$

where $F_{C r}(r, i)$ and $F_{P r}(r, i)$ represent the consumption-based and production-based emissions for country $\mathrm{r}$ in year $\mathrm{i}$, respectively. Imports $(r, i)$ and $\operatorname{Exports}(r, i)$ are the annual trade of goods and services from each country r. $\operatorname{COEF}(r, i)$ is the "production intensity" estimated $\left(\mathrm{CO}_{2}\right.$ emissions per unit of "Gross Productive Output") for country $\mathrm{r}$ in year $\mathrm{i}$. This is a compound indicator which represents changes of emission factors, technology, energy uses and production method etc (SI Section 1). "Gross Productive Output" equals GDP plus imports minus "imported elements" (Yang et al 2014). $C O E F_{i m}(r, i)$ refers to "importation intensity" which is calculated based on "production intensity" estimates. The constraints in Equation 1 mean that in each year the total imports equals exports of embodied emissions, and also that total territorial emissions equals consumption-based emissions. This "substance conservation" is achieved in each simulation by setting importing and consumption-based emissions to exporting and territorial ones respectively (SI Section 2). Theoritically speaking, LCBA2 resembles a simple version of EEBT-style Multi-regional input output model (Peters, ) without sectoral details (SI Section 1).

Instead of using a globally uniform "importation intensity" $C O E F_{i m}(i)$ for all countries as in original LCBA model (Yang et al 2014), we first classify 164 countries into 3 groups (SI Section 3) using a hierarchical clustering method based on a dynamic time warping (DTW) algorithm. The "importation intensities" for the 22 largest importing countries (SI Section 4) are then weighted using their import distribution between these 3 groups, while the remaining countries are weighted according to their mean global imports share. These 22 countries are all large developed or developing countries and they contribute $60 \%-77 \%$ of total imports each year during 1948-2012. What is more, their bilateral imports data are recorded much better and normally over a longer time span in the UNcomtrade database than those for other countries.

Therefore, two crucial issues in the LCBA2 model are to estimate the "production intensities" 
and the "importation intensities". Because it is difficult to separate the various imported elements that comprise final use items, GDP is treated as lower-bound of "Gross Productive Output" (domestic elements in final use items plus exports, see Yang et al 2014) and GDP plus imports is treated as the upper-bound. Combining these boundaries with production-based emissions gives bands of estimated "production intensities". We implement a Monte Carlo approach to choose particular $\operatorname{COEF}(r, i)$ from within these bands and calculate consumption-based emissions for all 164 countries and 64 years in each trial simulation. We typically run 10000 simulations in the Monte Carlo ensemble and use the $2.5 \%$ and $97.5 \%$ quintiles as upper and lower bounds of the $95 \%$ confidence interval of the median estimate.

Using these $\operatorname{COEF}(r, i)$ estimates, we replace globally uniform mean $\operatorname{COEF}_{\text {im }}(i)$ with weighted group averages $\operatorname{COEF}_{i m}(r, i)$ via three steps. Firstly the DTW algorithm separates the countries into 3 groups. Group 1 consists mainly of developed countries in North America and Western Europe. Group 2 includes developing countries in Eastern Europe, Central Asia and China. Group 3 comprises the remaining countries. Secondly, the "production intensity" for each group is calculated as the group mean based on $\operatorname{COEF}(r, i)$ estimates in each simulation. Thirdly, the importation intensities for each of the 22 largest importers are weighted based on their shares of imports among these 3 groups. Other countries are weighted using the global average imports shares.

Figure 1 demonstrates that the uniform importation intensities, as used in the original LCBA model, differ from the new intensities in LCBA2. Group 1 intensities are dramatically underestimated prior to 1980 and then slightly overestimated. Group 2 emission intensities are greatly underestimated for much of the period after 1950. Group 3 emission intensities are overestimated until approximately 1970 and are subsequently slightly underestimated. These obvious differences suggest utilizing grouping improves the LCBA2 model.

\subsection{Sources of data}

Merchandise trade data from 1948 to 2012 and service trade data from 1980 to 2012 were obtained from the World Trade Organization (WTO) based on the "general trade" recording system (WTO 2014). Services trade data before 1980 were supplemented by BPM 5 (Balance of Payments, version 5) datasets from the International Monetary Fund (IMF 2014). The departure point of 1948 was chosen because the GATT (General Agreement on Tariffs and Trade, the predecessor of WTO) was founded in that year, which marks the start of long-term and consistent trade statistics. Exports were valued at FOB (free on board) price, imports at CIF (cost insurance and freight) price and they were all counted in current US dollars. Detailed 
bilateral trade data between countries comes from the UNcomtrade database (UN 2014).

Nominal GDP (gross domestic product) in current US dollars (1960-2012) was derived from the World Bank WDI (World Development Indicators) database (World Bank 2014). GDPs before 1960 were calculated using 2 methods: (1) For the 52 largest emitters, which had an average consumption-based emissions between 1990 and 2008 greater than $50 \mathrm{Mt}$ (Peters et al 2011b), 1948-1959 GDPs were backdated using the real growth rates, the per capita growth rates and the population growth rates based on specific historical studies (Yang et al 2014). (2) For the remaining countries, the real growth rates are estimated from Maddison's historical PPP GDP (GDP converted to international dollars using purchasing power parity rates) data (Maddison 2010).

Production-based $\mathrm{CO}_{2}$ emissions comprised those emitted from fossil fuel combustion and cement production. Data on fossil fuels and cement production from 1980-2012 were taken from the U.S. Energy Information Administration (EIA) and the Carbon Dioxide Information Analysis Center (CDIAC), respectively (Boden et al 2013, EIA 2014). Because cement production data from the CDIAC ends in 2010, average values for the past 3 years were used to extrapolate the data for 2011 and 2012. Data before 1980 were supplemented with total emissions from the CDIAC. Production-based emissions of $\mathrm{CH}_{4}$ and $\mathrm{N}_{2} \mathrm{O}$ came from the EORA database (Lenzen et al 2012, 2013). $\mathrm{SO}_{2}$ emission data have 2 sources: the Socioeconomic Data and Applications Center (SEDAC, Smith et al 2011a, b) and EORA database. All the details in data sources are fully listed in SI section 5.

\section{Results and Discussion}

\subsection{Comparison of transfer emission results with the other 4 methods}

The 37 largest most significant countries included in all 5 methods (GRAM, TSTRD, EORA, LCBA and LCBA2), are compared in figure 2 and table S7. It is clear that most data points in TSTRD and GRAM are within $\pm 20 \%$ of LCBA2 with smaller differences of about $\pm 10 \%$ for EORA and LCBA. The differences between LCBA2 and LCBA are the smallest, as may be expected. Both TSTRD and EORA show lower emissions than LCBA2 for European countries. LCBA2 gives smaller emissions than EORA, GRAM and TSTRD for south-east Asian countries (Indonesia, Philippines, Thailand and Malaysia). LCBA2 gives smaller emissions for most European countries, and larger values for five important trade partners in China (namely the US, Japan, India, South Korea and Russia) than those in LCBA. Time series correlations between LCBA2 and the other methods are above 0.85 for most countries ( $<<0.05$; Table S7). In short, the new results in LCBA2 are similar to the existing four methods for large trading 
economies, but differences of $\pm 20 \%$ both in trend and magnitude are commonplace among the wider set of countries.

Patterns over 1995-2005 for six countries and each method are shown in figure 3. Changes in the times series of LCBA2 compared with LCBA reflect similar time variability in importation intensity for China's important trade partners (e.g. Russia and Japan) and many European countries (e.g. UK and France), as shown in figure 3. Disparate patterns between the two variables do also occur, for example China around 1995 and the US in 1990-2000 (figure 3). The changes in importation intensities in these cases should have increased the transfer emissions whereas the opposite occurred; this may be explained by the "conservation condition" applied in LCBA2 (Equation 1). LCBA2 time series are very similar to LCBA except for Hong Kong and Singapore (two main trading economies) which changed dramatically. The main differences between LCBA2 and LCBA emissions are due to the new group method and use of the UNcomtrade bilateral data.

\subsection{Across-method differences}

Because the executable files for the EORA, TSTRD and GRAM methods are not publically available, we assess the across-method differences by using each of their input territorial emission datasets in the LCBA2 method. For instance, 127 countries over the period 1970-2011 and 1970-1990 have been estimated using EORA (Kanemoto et al, 2014) and can be compared with the results from the LCBA2 (figure 4 and table S8). While using the same emission data does reduce the relative differences in the results, and improves the correlation between the time series, large differences still exist for many countries. Using the same input, $45 \%$ countries have differences below 10\% including all the largest emitters, and around $70 \%$ show average emission differences within $\pm 20 \%$ (table S8). Correlation coefficients, (figure 4) rise when using the same inputs, especially in the period 1970-1990 for the smaller countries. Whether use the same inputs or not, correlations are always above 0.8 for most countries and the values are above 0.9 for many large economies in both periods. From the single year perspective, 2005 is used as example to demonstrate the country-by-country distribution of consumption based emission differences in figure 5 , and does not significantly change with the same input datasets. Over $80 \%$ countries have differences between methods within $\pm 25 \%$, and for the largest emitters (such as the US, China, India and Russia) the biases are often below $\pm 10 \%$ whether the same input data is used or not.

Similar analyses can be done for TSTRD with 92 countries over the period 1990-2008 (SI section 6 and table S9). The average emission differences between LCBA2 and TSTRD are within $\pm 10 \%$ for half of the countries, especially for large emitters, and below $\pm 20 \%$ for $70 \%$ 
countries. Many big emitting country differences in 2005, are improved after using the same inputs, however, the whole distribution pattern is not changed: nearly $3 / 4$ countries have differences less than $\pm 25 \%$ and the large economies are within $\pm 10 \%$. For GRAM, 51 countries over the period 1995-2005, (see SI section 6 and table S10), nearly all the countries are within $\pm 25 \%$ of LCBA2, and all large emitter have differences below $\pm 10 \%$ except for Russia (20\%) and South Korea (24\%). No significant improvement in correlation coefficients occurs for common input data. Large emitters tend to have correlation coefficients around 0.9 and $70 \%$ countries have correlations above 0.7 whether the using the same data or not, and the 2005 year analysis share similar responses as TSTRD and EORA.

In summary, using the same input data in 3 methods reduces emissions differences between methods, but is relatively minor compared with intrinsic across-method differences both as time series and for single years. Large emitters tend to have average emission differences within $\pm 10 \%$ and $70 \%$ or more countries have values within $\pm 25 \%$. Therefore, it is the calculation framework (the matrix in GRAM, EORA, TSTRD and the GDP, trade data in LCBA2) that causes the primary differences among different methods.

\subsection{Transfer $\mathrm{CO}_{2}$ emissions estimates over the long term}

Since 1948, strikingly large increases in transferred emissions steadily occurred except for 2009, contributing 6.5\% 28.6\% of annual territorial emissions. The LCBA2 results indicated that cumulative emissions transferred between ANNEXI (AXI) and non-ANNEXI (NXI) group (as declared in Kyoto Protocol) reached as much as 36 [22-49] Gt in 2012. Transferred emissions for the 1948-1990 period contribute approximately 8\% [-7\% 15\%] to this cumulative volume. This share indicates that transferred emissions in 1948-1990 period cannot be simply ignored in future historical emission accounting even though trade volumes were relatively limited in that period. This is especially true when we try to simulate climate impacts of transfer emissions using long term emission inventories. Moreover, because trade volumes before 1948 were much smaller than current volumes, earlier transferred emissions can be safely assumed to be negligible. Therefore, long term (1850-2012) consumption-based emissions before 1948 can also be derived using territorial emissions as substitutes.

Annual emission transfers between AXI and NXI parties have increased sharply since the early 1980s, as has the traded fraction of total emissions (see figure 6). Although the Great Recession and the following European Debt Crisis essentially halted growth, transferred emissions continued to represent approximately $7 \%$ of global carbon emissions. Furthermore, the slowly reviving economy since 2010 has marked a renewed growth of transferred emissions despite a 
declining share. Generally speaking, transferred emissions have contributed an historic $36 \mathrm{Gt}$ $\mathrm{CO}_{2}$ of cumulative emissions to AXI countries and have grown rapidly during the past 30 years (up to $8 \%$ of total emissions). It is likely to continue to be influential in the near future as shown by the rebound in transfer amounts in 2011 and 2012.

Furthermore, the LCBA2 results independently confirm previous findings regarding the efficacy of the Kyoto Protocol. Figure 7 compares changes in territorial and consumption-based emissions from 1990 to 2012 with the Kyoto Protocol reduction commitments. Ignoring transfer emissions, the United States has increased territorial emissions by $4 \%$, despite its pledged $7 \%$ reduction. This percentage change soars to $17 \%$ when taking emission transfers into consideration. Similar trends can be seen for Australia, Canada, Spain, Netherlands and Japan, all of which fail in both accounting perspectives. The picture in the UK is different. The UK appeared to be succeeding (-17\% in contrast to its $-14 \%$ target) from the territorial perspective. However, taking transfer emissions into account shows this to be an illusion (15\% increases). The results are similar for France, Germany and Italy. In the case of those countries that have done better than their Kyoto targets (Russia, Poland and Ukraine), factoring in trade further increased their success by $6 \%-100 \%$. In short, emission transfers can be significant and may be comparable in magnitude to territorial emissions as shown in figure 7 .

\subsection{Non- $\mathrm{CO}_{2}$ and Regional pollutant transfers}

Using the LCBA2 model, we also calculated the 1970-2011 consumption-based emissions for $\mathrm{N}_{2} \mathrm{O}, \mathrm{CH}_{4}$ and $\mathrm{SO}_{2}$ (as shown in figure 8) based on territorial data in the EORA (Lenzen et al 2012, 2013) and SEDAC database (Smith et al 2011a, b). The ratios of transferred emissions to annual totals in $\mathrm{NO}_{2}(13 \% \sim 34 \%), \mathrm{CH}_{4}(9 \sim 29 \%)$ and $\mathrm{SO}_{2}(11 \% \sim 31 \%$ for both EORA and SEDAC) are all higher than $\mathrm{CO}_{2}(9 \% \sim 27 \%)$ during 1970-2012. We find similar results for the shift shares between AXI group and NXI group of non- $\mathrm{CO}_{2}$ GHG emissions, namely $\mathrm{NO}_{2}$ (6-10\%), $\mathrm{CH}_{4}(8-12 \%)$ and $\mathrm{SO}_{2}$ (8-12\% for EORA and SEDAC) comparing to $\mathrm{CO}_{2}(4 \%-8 \%)$ since the year 2000. Consumption-based emissions for $\mathrm{CH}_{4}$ were nearly the same as those in EORA, while results of $\mathrm{N}_{2} \mathrm{O}$ differed. Territorial emissions of $\mathrm{CH}_{4}$ in the AXI group started to decline after approximately 1990 and remained nearly constant in recent years, while emissions from the NXI group continued growing (by $1.9 \%$ on average per year since 2000), enlarging the gap between the two groups. When we considered transferred emissions, the gap was greatly reduced in both the LCBA2 and EORA estimates. Embodied $\mathrm{CH}_{4}$ emissions transferred to AXI countries account for $32 \%$ [25\%-39\%] of AXI total emissions and $4 \%-12 \%$ of annual total emissions in LCBA2, indicating an important contribution from trade. We must also mention that territorial emissions given by Kanemoto et al (2014) based on EORA database are considerably smaller than expected for all 3 gases (by nearly an order of magnitude for $\mathrm{N}_{2} \mathrm{O}$, but 
only $15 \%$ for $\mathrm{CH}_{4}$ ), which may cause some confusion (SI Section 7). In the case of $\mathrm{N}_{2} \mathrm{O}$, EORA results indicated always larger consumption-based emissions for the NXI group than the AXI group except for 2000 and 2004. However, the LCBA2 results showed more significant transferred emissions and indicate that the AXI group had higher consumption-based emissions than the NXI group before the mid-2000s. Since then, both results (LCBA2 and EORA) displayed an apparently growing gap with emissions rising in the NXI group (1.0\% per year) and declining in the AXI group (-1.5\% per year). The large fluctuations for $\mathrm{CH}_{4}$ and $\mathrm{N}_{2} \mathrm{O}$ in 1991 (see figure 8) can be explained by the abnormally emissions embodied in exports from the former USSR (see EORA database), which is a result of EORA's optimization and input-output calculation procedures (SI Section 8). Moreover, spikes in $\mathrm{N}_{2} \mathrm{O}$ and $\mathrm{CH}_{4}$ emissions from the NXI group in 1982 and 1997 were due to sudden emission changes in Indonesia (SI Section 8) and spikes in $\mathrm{N}_{2} \mathrm{O}$ emissions from the AXI group in 1981 and 2000 can be ascribed to the sharp fluctuations in territorial emissions in the USA, the UK, Japan and Australia.

The regional pollutant $\mathrm{SO}_{2}$ (1948-2005) based on SEDAC database (Smith et al 2011a, b) displays a similar pattern as $\mathrm{CO}_{2}$, in which emissions (both terrestrial and consumption-based) in the NXI group continued growing while those from the AXI group have been declining since the late 1970s. $\mathrm{SO}_{2}$ emission transfers were minor before 1970 and have been rapidly growing ever since. Using different data sources, LCBA2 and Kanemoto et al (2014) give similar territorial and consumption-based $\mathrm{SO}_{2}$ emissions since 1970, although again confusingly results in Kanemoto et al (2014) are always larger than EORA despite them sharing the same data source (SI Section 7).

In summary, the ratios of transferred emissions to annual totals in $\mathrm{NO}_{2}(13 \% \sim 34 \%), \mathrm{CH}_{4}$ (9 29\%) and $\mathrm{SO}_{2}\left(11 \% \sim 31 \%\right.$ for both EORA and SEDAC) are all higher than $\mathrm{CO}_{2}(9 \% \sim 27 \%)$ for 1970-2012. And so are the relative changes in share between AXI and NXI groups. The emission gaps between the AXI and NXI group for all 3 gases grew in both territorial and consumption-based perspectives. Comparisons of $\mathrm{CH}_{4}, \mathrm{~N}_{2} \mathrm{O}$ and $\mathrm{SO}_{2}$ in LCBA2 with EORA are in general consistent despite some difference before the mid-2000s for $\mathrm{N}_{2} \mathrm{O}$. Since EORA and LCBA2 have very different calculation framework, the similarity in results validates LCBA2, at least for $\mathrm{CH}_{4}$ and $\mathrm{SO}_{2}$.

\section{Conclusions}

This work focuses on improving the original LCBA model and backdating historical emissions with enhanced resolution. Several key findings can be drawn. (1) Using LCBA2, one can estimate transfer emissions with improved accuracy for 164 countries from 1948 to 2012. The 
new results in LCBA2 are in general reasonably close to the 3 other existing methods with similar trends and magnitudes, especially for the largest emitters. Significant changes from the original LCBA arise for European countries and China's important trade partners. These large changes are due to bringing imports structure into account. (2) Results reflect that cumulative emissions transferred between the AXI and NXI groups are up to $36 \mathrm{Gt} \mathrm{CO}_{2}$ since 1948 and $8.3 \%$ of these emissions occurred in the period of 1948-1990. Since 1990, transfer emissions rose dramatically (from 2\% to 8\% of annual total emissions) and recent data in 2011-2012 indicate a rebounding trend along with the reviving global economy. (3) LCBA2 results independently confirm previous findings regarding the efficacy of the Kyoto Protocol. (4) The ratios of transferred emissions to annual totals in $\mathrm{NO}_{2}(13 \% \sim 34 \%), \mathrm{CH}_{4}(9 \sim 29 \%)$ and $\mathrm{SO}_{2}(11 \% \sim 31 \%$ for both EORA and SEDAC) are all higher than $\mathrm{CO}_{2}(9 \% \sim 27 \%)$ in 1970-2012. Their relative changes in share between AXI and NXI groups are also higher. (5) LCBA2 results are comparable for $\mathrm{CH}_{4}, \mathrm{~N}_{2} \mathrm{O}$ and $\mathrm{SO}_{2}$ with those from EORA despite a difference before mid-2000s for $\mathrm{N}_{2} \mathrm{O}$. Since EORA and LCBA2 have very different calculation methods, this similarity provides some validation for LCBA2. (6) Across-method error analysis shows that it is the calculation framework that causes the differences among different methods rather than choice of input territorial emissions.

In general, the LCBA2 model indicates significant emissions shifts occur through international trade, which have grown in recent decades, not only for $\mathrm{CO}_{2}$ but also for other pollutants. And the LCBA2 model provides a useful and succinct method of estimating historical transfer and consumption-based emissions. These emissions could be used as external forcing for future climate modeling that targets at investigating counties responsibility for historical climate change and climatic effect of transferred GHGs emissions.

Acknowledgements The work is funded by the National Key Program for Global Change Research of China (2012CB9557), the National Natural Science Foundation of China (41175125, 41575001), the National level Major Incubation Project of Guangdong Province, China (2014GKXM058) and the National Science Foundation for Young Scholars of China (41505068).

\section{References}

Aichele R and Felbermayr G 2012 Kyoto and the carbon footprint of nations Journal of Environmental Economics and Management 63 336-354 DOI: http://dx.doi.org/10.1016/j.jeem.2011.10.005 .

Andrew R M, Davis S J and Peters G P 2013 Climate policy and dependence on traded carbon Environmental Research Letters 8034011 DOI: 10.1088/1748-9326/8/3/034011 .

Andrew R M and Peters G P 2013 A MULTI-REGION INPUT-OUTPUT TABLE BASED ON THE 
GLOBAL TRADE ANALYSIS PROJECT DATABASE (GTAP-MRIO) Economic Systems Research 25(1) 99-121 DOI: 10.1080/09535314.2012.761953.

Arto I, Jose Manuel Rueda C, Genty A, Villanueva Krzyzaniak A and Valeria A 2012. Global Resources Use and Pollution: Vol. I, Production, Consumption and Trade (1995-2008). Institute for Prospective and Technological Studies, Joint Research Centre.

Arto I, Rueda-Cantuche J M and Peters G P 2014 COMPARING THE GTAP-MRIO AND WIOD DATABASES FOR CARBON FOOTPRINT ANALYSIS Economic Systems Research 26(3) 327-353 DOI: 10.1080/09535314.2014.939949.

Baiocchi G and Minx J C 2010 Understanding Changes in the UK's $\mathrm{CO}_{2}$ Emissions: A Global Perspective Environmental Science \& Technology 44 1177-1184 DOI: 10.1021/es902662h .

Barrett J, Peters G, Wiedmann T, Scott K, Lenzen M, Roelich K and Le Quéré C 2013 Consumption-based GHG emission accounting: a UK case study Climate Policy 13 451-470 DOI: $10.1080 / 14693062.2013 .788858$.

Boden T A, Marland G AND ANDres R J 2013 Global, Regional, and National Fossil-Fuel CO Emissions Carbon Dioxide Information Analysis Center, Oak Ridge National Laboratory, U.S. Department of Energy, Oak Ridge, Tenn., U.S.A. DOI: 10.3334/CDIAC/00001_V2013.

Branger F and Quirion P 2014 Climate policy and the 'carbon haven' effect Wiley Interdisciplinary Reviews: Climate Change 5 53-71 DOI: 10.1002/wcc.245 .

Caldeira K and Davis S J 2011 Accounting for carbon dioxide emissions: A matter of time Proceedings of the National Academy of Sciences 108 8533-8534 DOI: 10.1073/pnas.1106517108 .

Davis S J and Caldeira K 2010 Consumption-based accounting of $\mathrm{CO}_{2}$ emissions Proceedings of the National Academy of Sciences $107 \quad 5687-5692$ DOI: http://dx.doi.org/10.1073/pnas.0906974107 .

Davis S J, Peters G P and Caldeira K 2011 The supply chain of $\mathrm{CO}_{2}$ emissions Proceedings of the National Academy of Sciences $\mathbf{1 0 8}$ 18554-18559 DOI: http://dx.doi.org/10.1073/pnas.1107409108 .

Dietzenbacher E, Los B, Stehrer R, Timmer M and De Vries G 2013 THE CONSTRUCTION OF WORLD INPUT-OUTPUT TABLES IN THE WIOD PROJECT Economic Systems Research 25 71-98 DOI: 10.1080/09535314.2012.761180.

EIA 2014 International Energy Statistics (available: http://www.eia.gov/cfapps/ipdbproject/IEDIndex3.cfm).

Geschke A, Wood R, Kanemoto K, Lenzen M and Moran D 2014 INVESTIGATING ALTERNATIVE APPROACHES TO HARMONISE MULTI-REGIONAL INPUT-OUTPUT DATA Economic Systems Research 26(3) 354-385 DOI: 10.1080/09535314.2014.937069 .

Guan D, Peters G P, Weber C L and Hubacek K 2009 Journey to world top emitter: An analysis of the driving forces of China's recent $\mathrm{CO}_{2}$ emissions surge Geophysical Research Letters 36 L04709 DOI: $10.1029 / 2008 \mathrm{gl} 1036540$.

IMF 2014 Balance of Payment version 5 (available: http://elibrary-data.imf.org/QueryBuilder.aspx?key=19784654\&s=322).

Inomata S and Owen A 2014 COMPARATIVE EVALUATION OF MRIO DATABASES Economic 
Systems Research 26 239-244 DOI: 10.1080/09535314.2014.940856 .

Jakob M and Marschinski R 2013 Interpreting trade-related $\mathrm{CO}_{2}$ emission transfers Nature Clim. Change 3 19-23 DOI: http://dx.doi.org/10.1038/nclimate1630 .

Jakob M, Marschinski R and Hübler M 2013 Between a Rock and a Hard Place: A Trade-Theory Analysis of Leakage Under Production- and Consumption-Based Policies Environmental and Resource Economics 56 47-72 DOI: 10.1007/s10640-013-9638-y .

Jakob M, Steckel J C and Edenhofer O 2014 Consumption- Versus Production-Based Emission Policies Annual Review of Resource Economics 6 297-318 DOI: 10.1146/annurev-resource-100913-012342 .

Kanemoto K, Moran D, Lenzen M and Geschke A 2014 International trade undermines national emission reduction targets: New evidence from air pollution Global Environmental Change 24 52-59 DOI: 10.1016/j.gloenvcha.2013.09.008 .

Lenzen M, Kanemoto K, Moran D and Geschke A 2012 Mapping the Structure of the World Economy Environmental Science \& Technology $46 \quad 8374-8381 \quad$ DOI: http://dx.doi.org/10.1021/es300171x .

Lenzen M, Moran D, Kanemoto K and Geschke A 2013 BUILDING EORA: A GLOBAL MULTI-REGION INPUT-OUTPUT DATABASE AT HIGH COUNTRY AND SECTOR RESOLUTION Economic Systems Research $25 \quad 20-49$ DOI: http://dx.doi.org/10.1080/09535314.2013.769938 .

Lenzen M, Pade L-L and Munksgaard J $2004 \mathrm{CO}_{2}$ Multipliers in Multiregion Input-Output Models Economic Systems Research 16 391-412 DOI: 10.1080/0953531042000304272 .

Liu L 2015 A critical examination of the consumption-based accounting approach: has the blaming of consumers gone too far? Wiley Interdisciplinary Reviews: Climate Change 6 1-8 DOI: $10.1002 /$ wcc. 325 .

Maddison A 2010 Statistics on World Population, GDP and Per Capita GDP, 1-2008 AD (Horizontal file) University of Groningen (available: http://www.ggdc.net/maddison/oriindex.htm) .

Meng B, Zhang Y and Inomata S 2013 COMPILATION AND APPLICATIONS OF IDE-JETRO'S INTERNATIONAL INPUT-OUTPUT TABLES Economic Systems Research 25(1) 122-142 DOI: $10.1080 / 09535314.2012 .761597$.

Miller R E and Blair P D 2009 Input-Output Analysis: Foundations and Extensions New York USA, Cambridge University Press.

Minx J C, Baiocchi G, Peters G P, Weber C L, Guan D and Hubacek K 2011 A "Carbonizing Dragon”: China's Fast Growing $\mathrm{CO}_{2}$ Emissions Revisited Environmental Science \& Technology 45 9144-9153 DOI: 10.1021/es201497m .

Moran D and Wood R 2014 CONVERGENCE BETWEEN THE EORA, WIOD, EXIOBASE, AND OPENEU'S CONSUMPTION-BASED CARBON ACCOUNTS Economic Systems Research 26(3) 245-261 DOI: 10.1080/09535314.2014.935298 .

Nakano S, Okamura A, Sakurai N, Suzuki M, Tojo Y and Yamano N 2009 The Measurement of $\mathrm{CO}_{2}$ Embodiments in International Trade OECD Science, Technology and Industry Working Papers, No. 2009/03, OECD Publishing. DOI: 10.1088/1748-9326/8/3/034011 . 
Owen A, Steen-Olsen K, Barrett J, Wiedmann T and Lenzen M 2014 A STRUCTURAL DECOMPOSITION APPROACH TO COMPARING MRIO DATABASES Economic Systems Research 26(3) 262-283 DOI: 10.1080/09535314.2014.935299 .

Peters G and Hertwich E 2004 Production Factors and Pollution Embodied in Trade: Theoretical Development Norwegian University of Science and Technology Industrial Ecology Programme http://urn.kb.se/resolve?urn=urn:nbn:no:ntnu:diva-1401.

Peters G, Marland G, Hertwich E, Saikku L, Rautiainen A and Kauppi P 2009 Trade, transport, and sinks extend the carbon dioxide responsibility of countries: An editorial essay Climatic Change $\mathbf{9 7}$ 379-388 DOI: 10.1007/s10584-009-9606-2 .

Peters G P 2008 From production-based to consumption-based national emission inventories ECOLOGICAL ECONOMICS 65 13-23 DOI: 10.1016/j.ecolecon.2007.10.014 .

Peters G P, Andrew $\mathrm{R}$ and Lennox J 2011a CONSTRUCTING AN ENVIRONMENTALLY-EXTENDED MULTI-REGIONAL INPUT-OUTPUT TABLE USING THE GTAP DATABASE Economic Systems Research 23 131-152 DOI: http://dx.doi.org/10.1080/09535314.2011.563234 .

Peters G P, Davis S J and Andrew R M 2012a A synthesis of carbon in international trade Biogeosciences Discuss. 9 3949-4023 DOI: http://dx.doi.org/10.5194/bgd-9-3949-2012 .

Peters G P and Hertwich E G $2008 \mathrm{CO}_{2}$ Embodied in International Trade with Implications for Global Climate Policy Environmental Science \& Technology 42 1401-1407 DOI: http://dx.doi.org/10.1021/es072023k .

Peters G P, Marland G, Le Quere C, Boden T, Canadell J G and Raupach M R 2012b CORRESPONDENCE: Rapid growth in $\mathrm{CO}_{2}$ emissions after the 2008-2009 global financial crisis Nature Climate Change 2 2-4 DOI: 10.1038/nclimate1332 .

Peters G P, Minx J C, Weber C L and Edenhofer O 2011b Growth in emission transfers via international trade from 1990 to 2008 Proceedings of the National Academy of Sciences 108 8903-8908 DOI: http://dx.doi.org/10.1073/pnas.1006388108 .

Smith S J, Van Aardenne J, Klimont Z, Andres R J, Volke A and Delgado Arias S 2011a Anthropogenic Sulfur Dioxide Emissions, 1850-2005: National and Regional Data Set by Source Category, Version 2.86 NASA Socioeconomic Data and Applications Center (SEDAC) http://dx.doi.org/10.7927/H49884X9.

Smith S J, Van Aardenne J, Klimont Z, Andres R J, Volke A and Delgado Arias S 2011b Anthropogenic Sulfur Dioxide Emissions: 1850-2005 Atmospheric Chemistry and Physics 11 1101-1116 http://dx.doi.org/10.5194/acp-11-1101-2011.

Steckel J, Kalkuhl M and Marschinski R 2010 Should carbon-exporting countries strive for consumption-based accounting in a global cap-and-trade regime? Climatic Change 100 779-786 DOI: 10.1007/s10584-010-9825-6 .

Steininger K, Lininger C, Droege S, Roser D, Tomlinson L and Meyer L 2014 Justice and cost effectiveness of consumption-based versus production-based approaches in the case of unilateral climate policies Global Environmental Change 24 75-87 DOI: http://dx.doi.org/10.1016/j.gloenvcha.2013.10.005 . 
Timer M P 2012 The World Input-Output Database (WIOD): Contents, Sources and Methods WIOD Working Paper Number 10 http://www.wiod.org/publications/papers/wiod10.pdf.

Tukker A and Dietzenbacher E 2013 GLOBAL MULTIREGIONAL INPUT-OUTPUT FRAMEWORKS: AN INTRODUCTION AND OUTLOOK Economic Systems Research 25 1-19 DOI: $10.1080 / 09535314.2012 .761179$.

UNITED NATIONS 2014 UN Comtrade Database (available: http://comtrade.un.org/data/).

Weber C L and Matthews S H 2007 Embodied Environmental Emissions in U.S. International Trade, 1997-2004 Environmental Science \& Technology 41 4875-4881 DOI: 10.1021/es0629110 .

Weber C L and Peters G P 2009 Climate change policy and international trade: Policy considerations in the US Energy Policy 37 432-440 DOI: http://dx.doi.org/10.1016/j.enpol.2008.09.073 .

Weber C L, Peters G P, Guan D and Hubacek K 2008 The contribution of Chinese exports to climate change Energy Policy 36 3572-3577 DOI: 10.1016/j.enpol.2008.06.009

T Wei, SL Yang, J C Moore et al. 2012 Developed and developing world responsibilities for historical climate change and CO2 mitigation 109(32): 12911-12915 DOI: 10.1073/pnas.1203282109 .

T Wei, W Dong, Q Yan et al. 2016. Developed and developing world contributions to climate system change based on carbon dioxide, methane and nitrous oxide emissions Advances in Atmospheric Sciences 33(5): 632-643 DOI: 10.1007/s00376-015-5141-4 .

Wiebe K S, Bruckner M, Giljum S and Lutz C 2012 CALCULATING ENERGY-RELATED $\mathrm{CO}_{2}$ EMISSIONS EMBODIED IN INTERNATIONAL TRADE USING A GLOBAL INPUTOUTPUT MODEL Economic Systems Research 24 113-139 DOI: http://dx.doi.org/10.1080/09535314.2011.643293 .

Wiedmann T, Wood R, Minx J C, Lenzen M, Guan D and Harris R 2010 A CARBON FOOTPRINT TIME SERIES OF THE UK - RESULTS FROM A MULTI-REGION INPUT-OUTPUT MODEL Economic Systems Research 22 19-42 DOI: 10.1080/09535311003612591 .

WORLD BANK 2014 GDP and imports of goods and services in current U.S. dollars (available: http://data.worldbank.org/data-catalog/world-development-indicators).

WTO 2014 Time Series on international trade (available: http://stat.wto.org/StatisticalProgram/WSDBStatProgramHome.aspx?Language=E).

Yang Z, Dong W, Wei T, Fu Y, Cui X, Moore J and Chou J 2014 Constructing long-term (1948-2011) consumption-based emissions inventories Journal of Cleaner Production DOI: 10.1016/j.jclepro.2014.03.053. 


\section{- Figure Captions:}

Figure 1 Comparison of Average Emission Intensities ( $\mathrm{Mt} \mathrm{CO}_{2}$ per GDP in current US \$) in 3 Groups and the Original Global Mean. Original Global Mean is the uniform importation intensity for all countries used in the original LCBA model (Yang et al 2014).

Figure 2 The differences between LCBA2 results and those in 4 other methods (EORA, GRAM, TSTRD and LCBA) for 37 countries over the period 1995-2005. The horizontal axis represents the average emission (for 1995-2005) percentage differences, while the vertical axis indicates the time series correlation coefficients. Colors represent geographical country location and the size of the circle is proportional to the average consumption based emissions in LCBA2.

Figure 3 Emission transfer (left column) and Importation intensity (right column) changes for six countries since 1970. The emission transfers come from the LCBA2 model (mean values and ranges), the original LCBA model (mean values) and 3 earlier models (TSTRD, GRAM and EORA). The importation intensities are the original global mean in LCBA and new ones in LCBA2.

Figure 4 The differences between LCBA2 results and those in EORA for 127 countries for 1970-2011 (top row) and 1990-2011 (bottom row), with the left column having different method input datasets and the right sharing the same EORA dataset. The horizontal axis shows the average emission percentage biases, while the vertical axis indicates the time series correlation coefficient.

Figure 5 The distribution of differences in consumption based emissions for EORA and LCBA2 using different (left) or the same (right) input territorial emissions for 2005. The inset figures demonstrate the whole range while the main plots reveal the distribution within $100 \%$.

Figure 6 Shift in share (left vertical axis) of total emissions and $\mathrm{CO}_{2}$ emission transfers (in million metric tons, right vertical axis) between AXI and NXI parties from 1948 to 2012

Figure 7 Percentage changes of emissions for large emitters in different accounting perspectives. The Kyoto Protocol reduction targets are shown with black dots. Percentage changes in territorial and consumption-based emissions from 1990 to 2012 are shown with red and green bars.

Figure 8 Historic emissions based on territorial (Prod) and consumption-based accounting (Cons) of $\mathrm{CH}_{4}$ (1970-2011), $\mathrm{N}_{2} \mathrm{O}$ (1970-2011) and $\mathrm{SO}_{2}$ (1948-2005) from for both developed countries (AXI parties) and developing countries (NXI parties). Earlier consumption-based EORA results from Kanemoto et al (2014) are also shown (without any changes). 
Figure 1

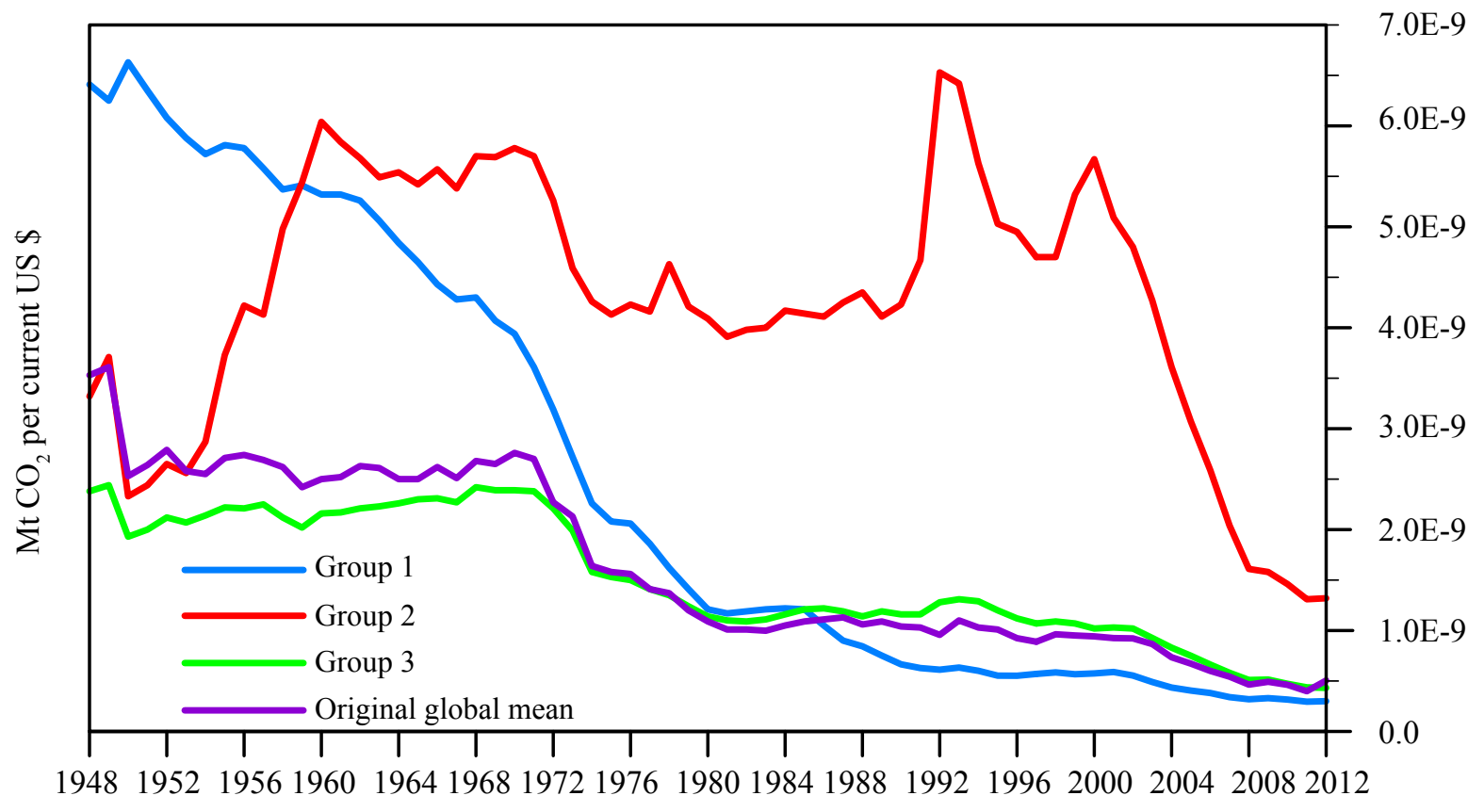



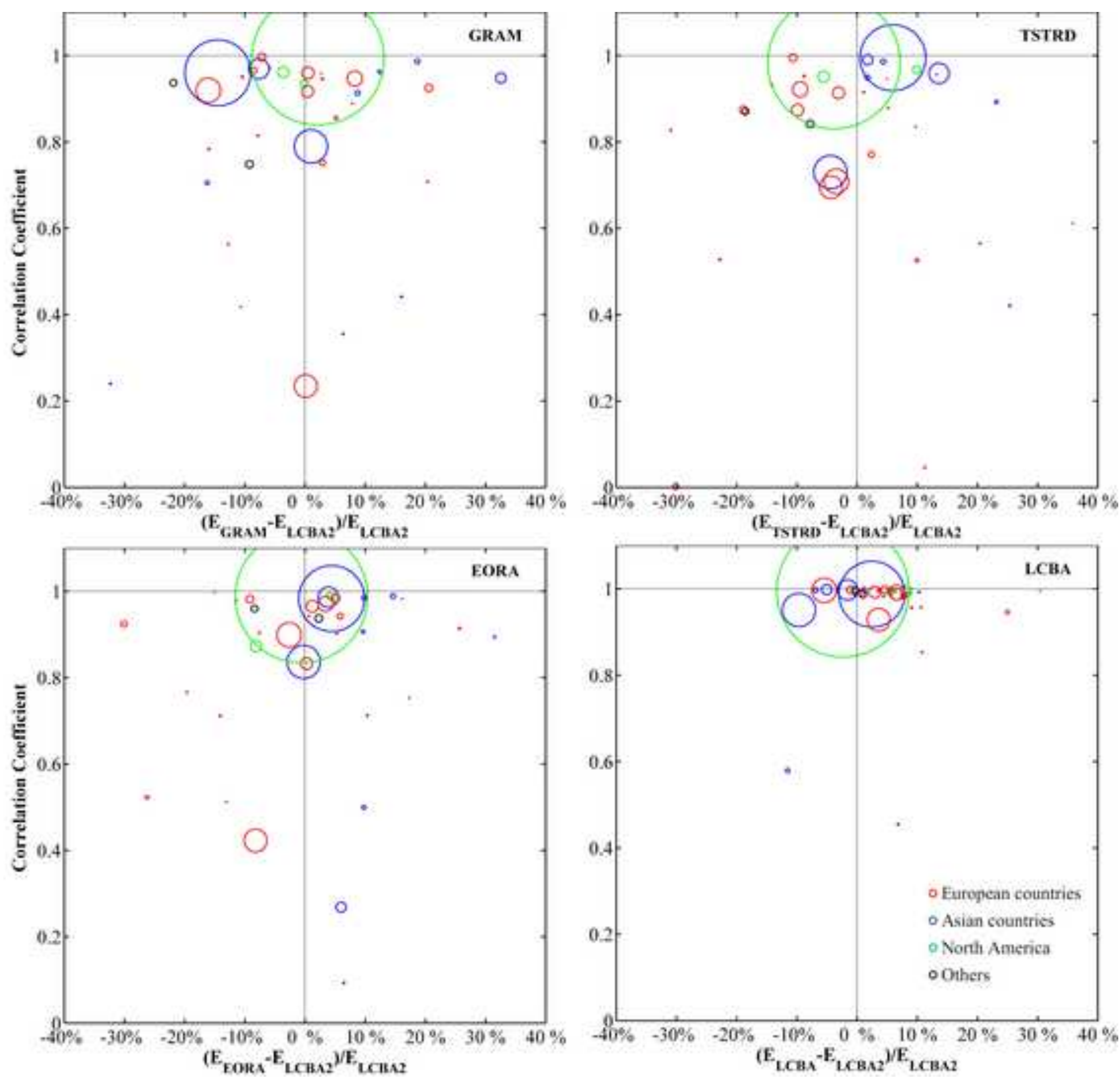

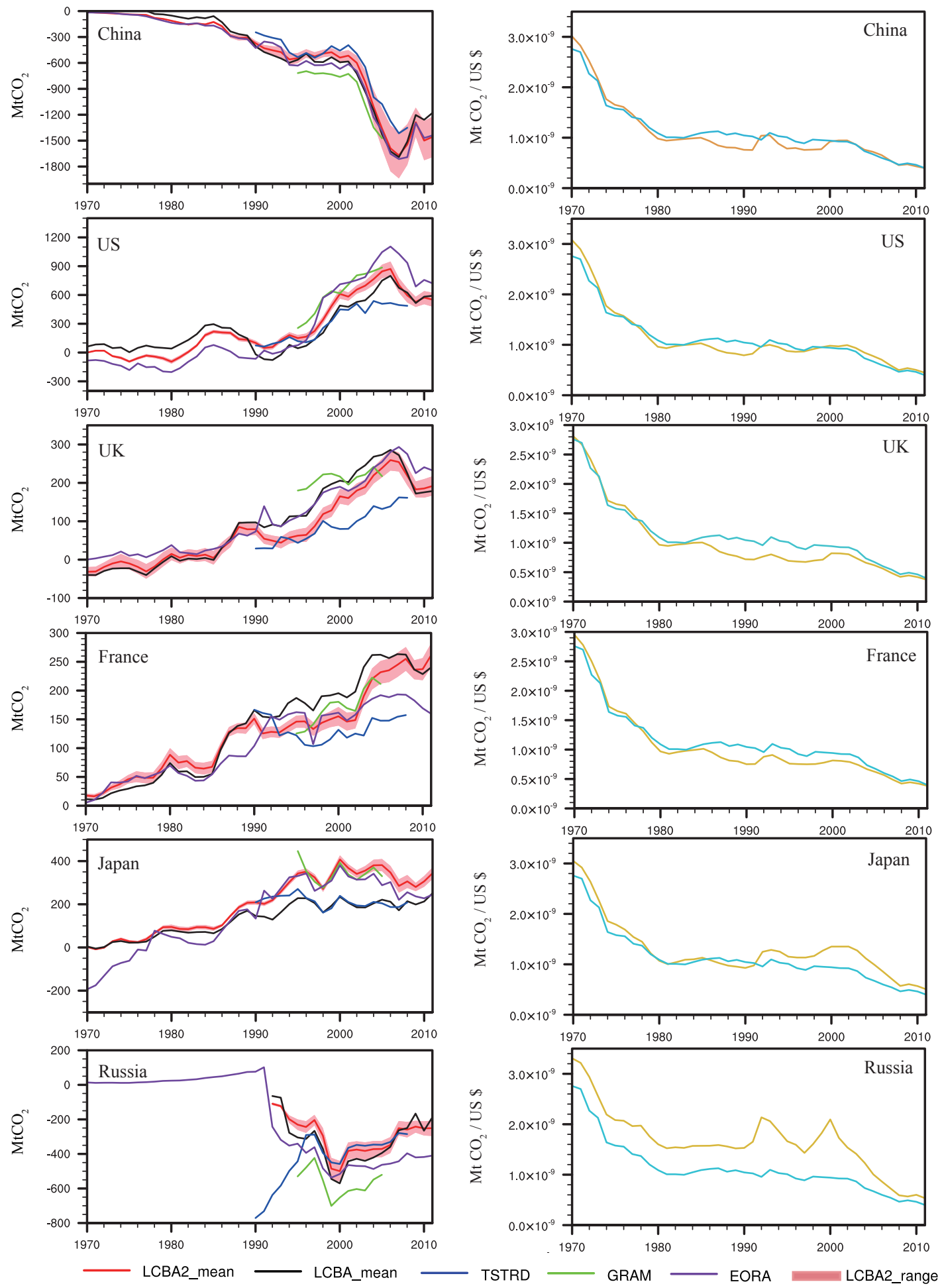

Importation Intensities

__ Original global mean 
Figure 4
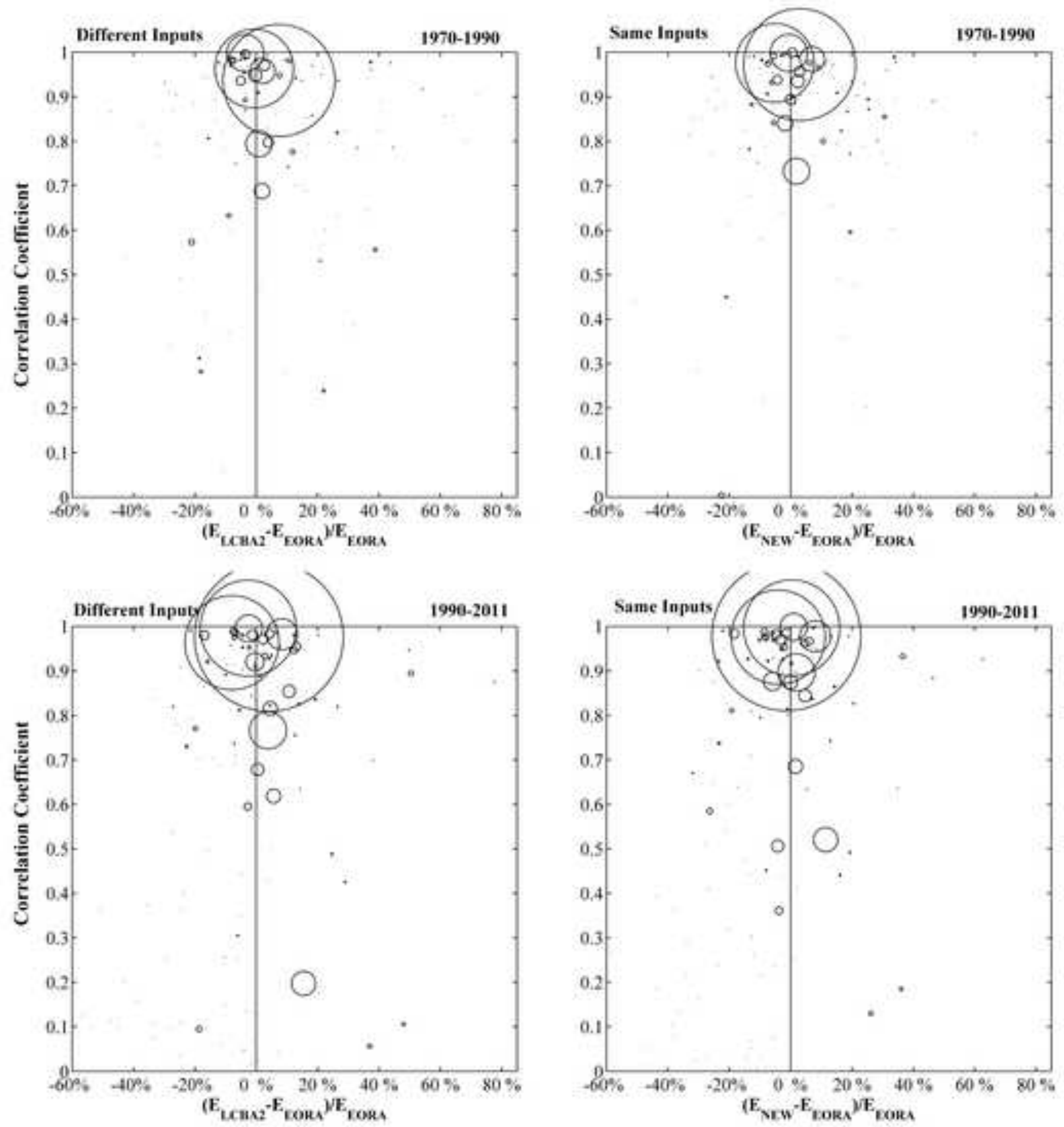


\section{Differenees with different Inputs}

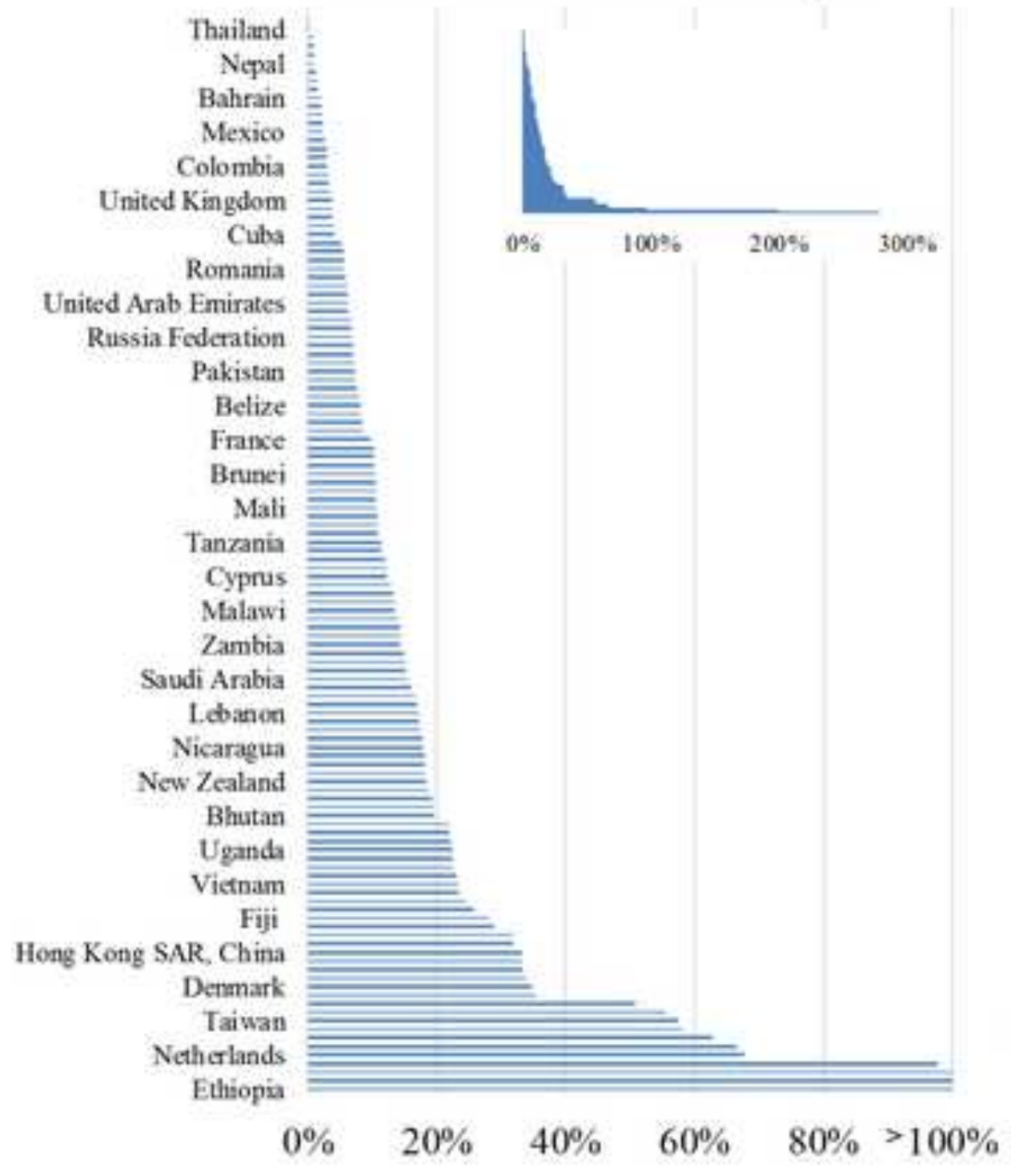

\section{Differences with same Inputs}

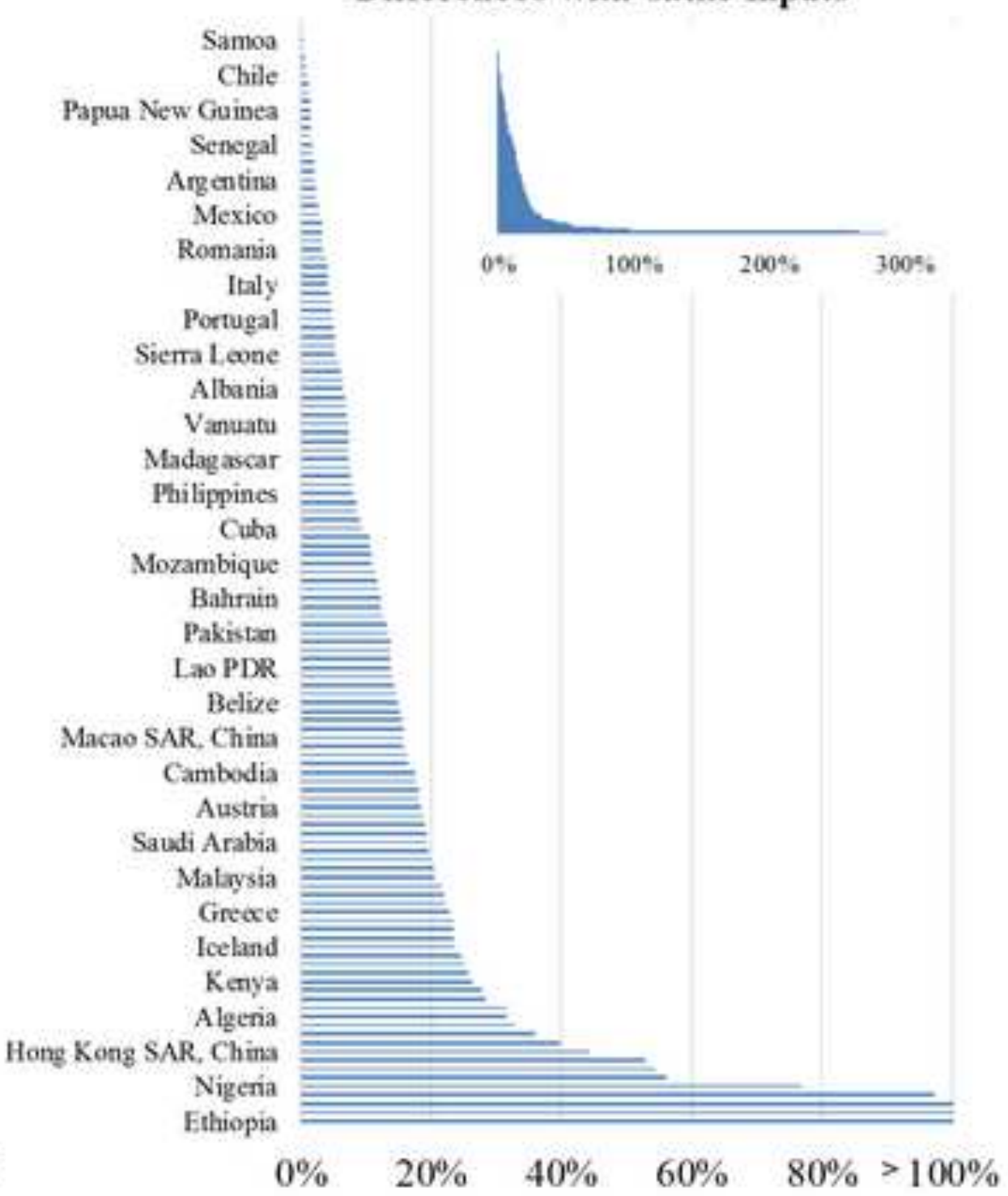




\section{Figure 6}

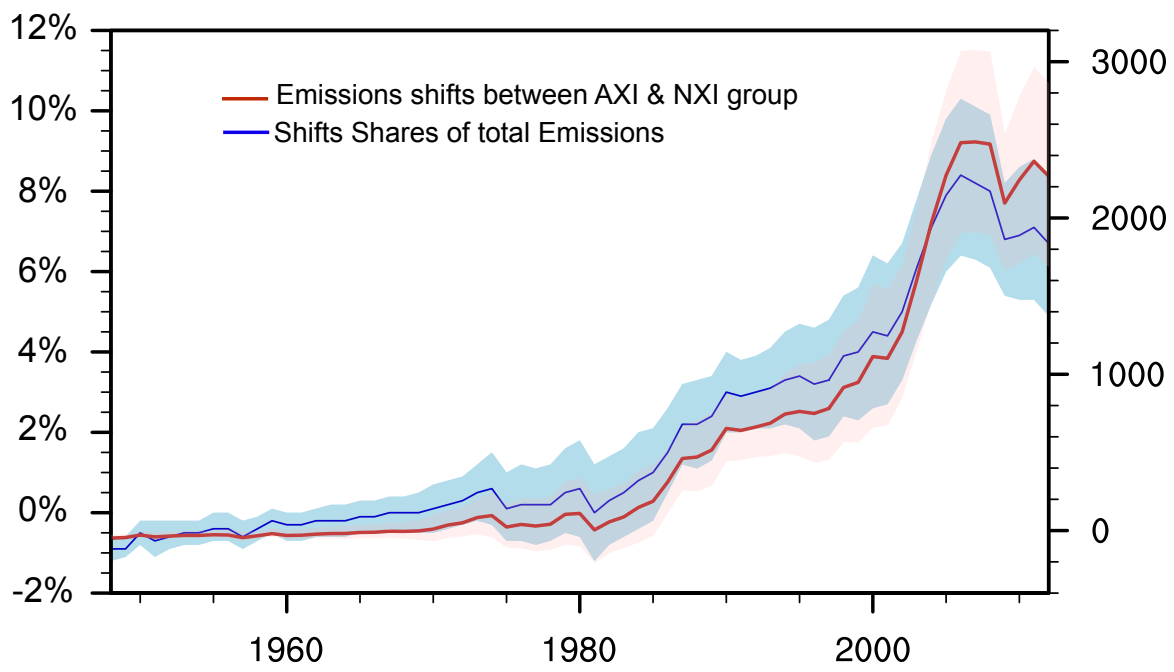


Figure 7

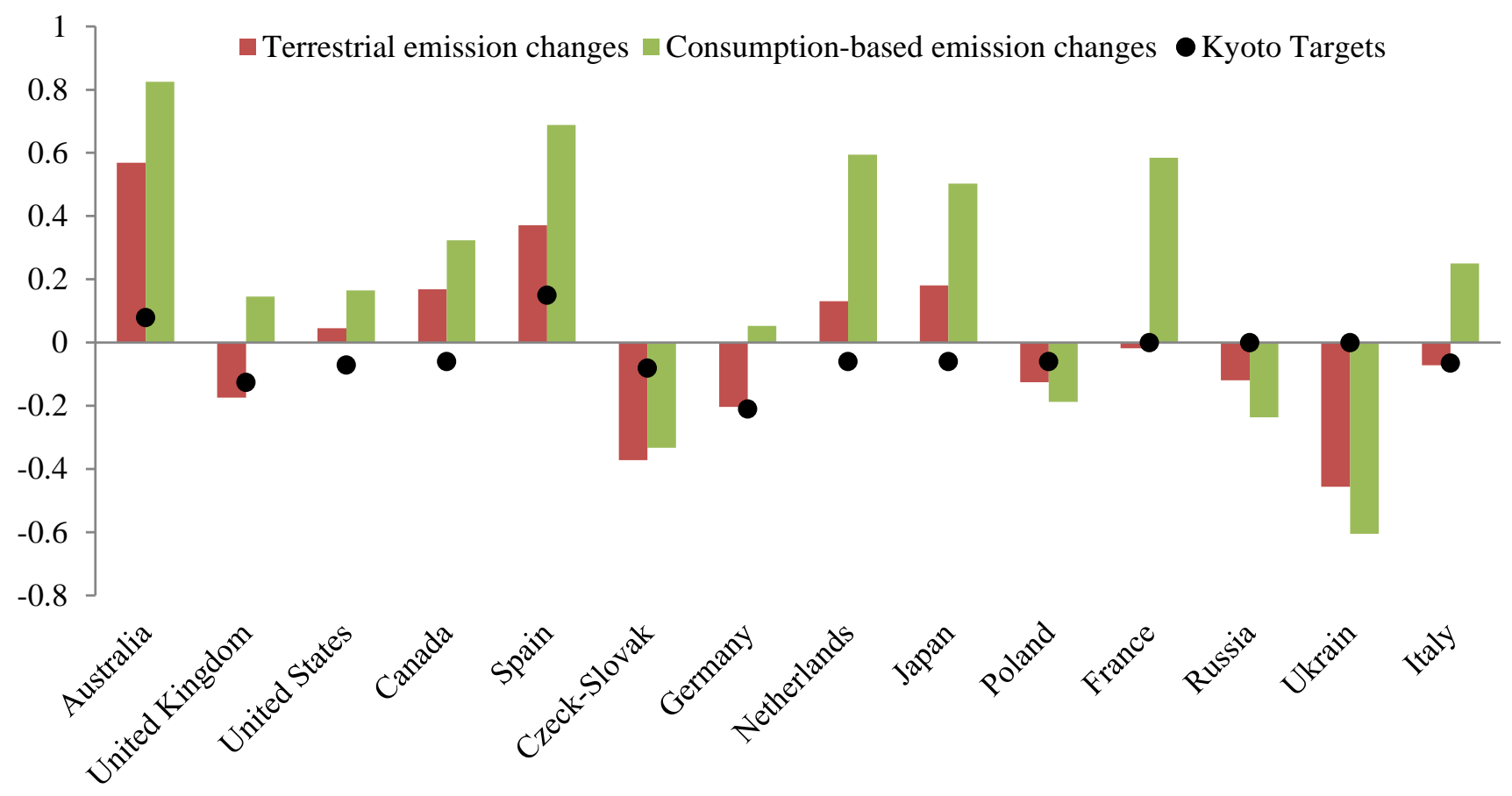



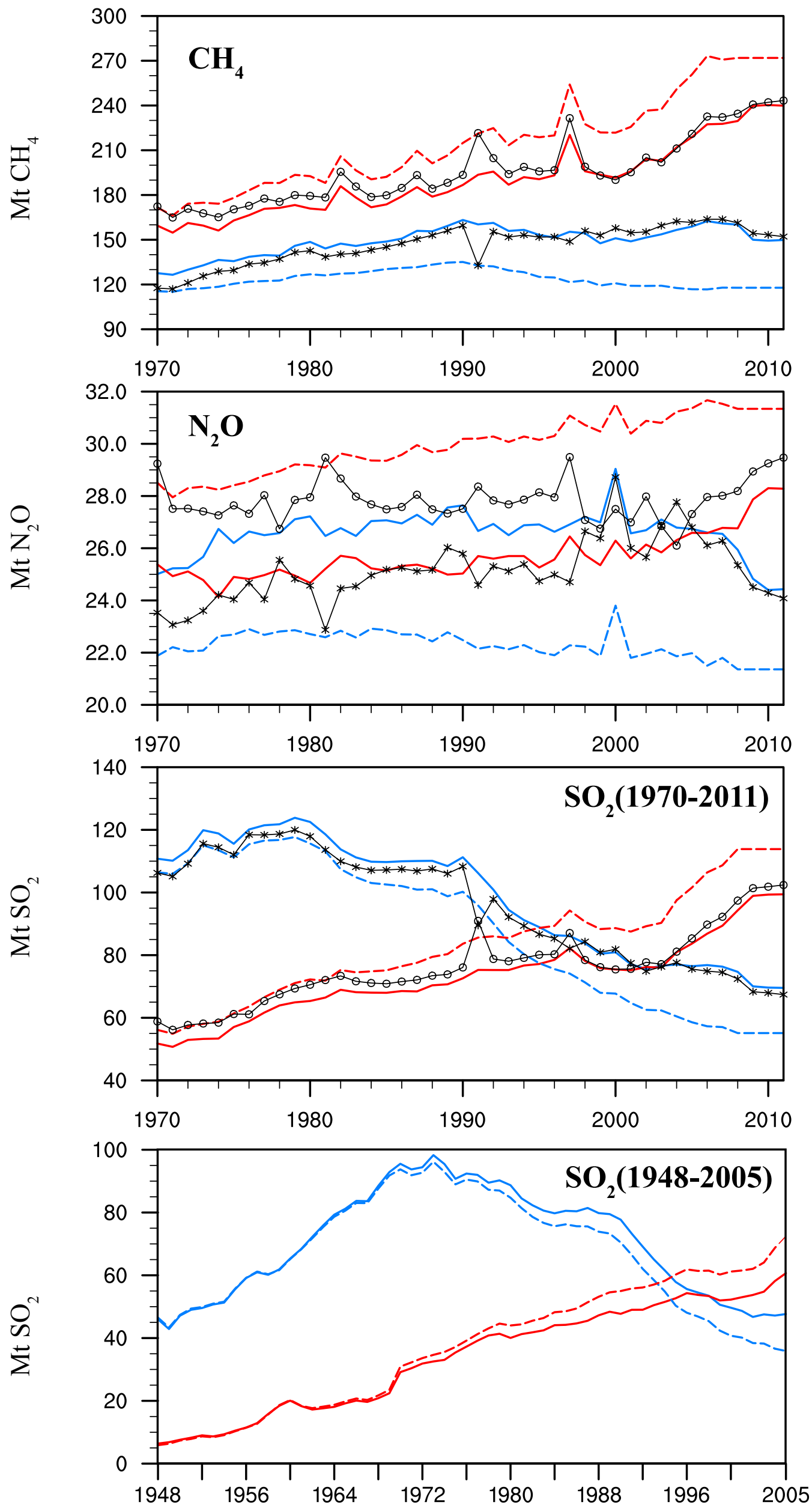

--- Prod_NX1 - - - Prod_AX1 Cons_NX1 C Cons_AX1 